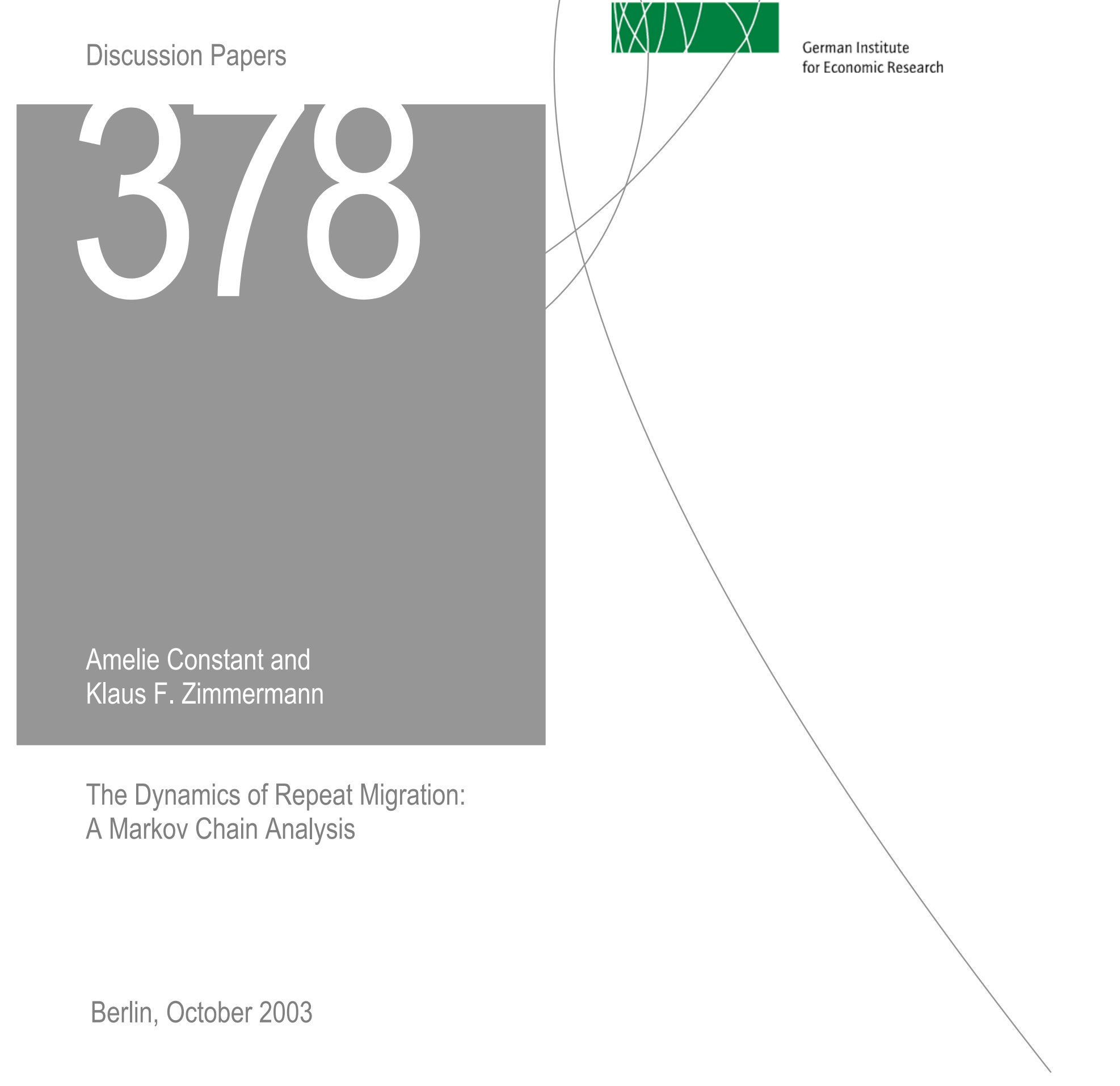


Opinions expressed in this paper are those of the author and do not necessarily reflect views of the Institute.

DIW Berlin

German Institute

for Economic Research

Königin-Luise-Str. 5

14195 Berlin,

Germany

Phone +49-30-897 89-0

Fax $\quad+49-30-89789-200$

www.diw.de

ISSN 1619-4535 


\title{
THE DYNAMICS OF REPEAT MIGRATION: A MARKOV CHAIN
}

\section{ANALYSIS}

\author{
Amelie Constant \\ University of Pennsylvania and IZA \\ aconstan@pop.upenn.edu \\ and \\ Klaus F. Zimmermann \\ Bonn University, IZA, and DIW Berlin \\ Zimmermann@iza.org
}

Draft: October 2003

\begin{abstract}
While the literature has established that there is substantial and highly selective return migration, the growing importance of repeat migration has been largely ignored. Using Markov chain analysis, this paper provides a modeling framework for repeated moves of migrants between the host and home countries. The Markov transition matrix between the states in two consecutive periods is parameterized and estimated using a logit specification and a large panel data with 14 waves. The analysis for Germany, the largest European immigration country, shows that more than $60 \%$ of the migrants are indeed repeat migrants. The out-migration per year is low, about $10 \%$. Migrants are more likely to leave again early after their arrival in Germany, and when they have social and familial bonds in the home country, but less likely when they have a job in Germany and speak the language well. Once out-migrated from Germany, the return probability is about $80 \%$ and guided mainly by remittances and family considerations.
\end{abstract}

Keywords: Repeat Migration, Guestworkers, Qualitative Choice Models, Duration Analysis, Markov Chain Analysis

JEL classification: F22; J61; C25; C41; C44

Corresponding author:

Klaus F. Zimmermann

IZA, P.O. Box 7240

D-53072 Bonn, Germany

Phone: +49228 3894200

Fax: +492283894210

Presented at the annual meeting of the Society of Labor Economists (SOLE) in Toronto, Canada, September 2003. We thank Jennifer Hunt and other conference participants for many useful comments. 


\section{INTRODUCTION}

The literature on migration has established that return migration is considerable and highly selective. Early contributions in the demography literature have shown that about $30 \%$ of the foreign-born individuals in the United States out-migrate again within a decade or two after arrival (Warren and Peck, 1980; Warren and Kraly, 1985). Jasso and Rosenzweig (1982) found that emigration rates varied substantially by nationality (ranging from $20 \%$ to $50 \%$ ) and concluded that both proximity to the United States and the relative attractiveness of the home country were good predictors of emigration. Another study on legal immigrants in the United States found that between 1960 and 1980 European immigrants were the most likely to emigrate, Asian immigrants were the least likely, and immigrants from the Western Hemisphere were in-between (Jasso and Rosenzweig, 1990).

Borjas' (1989) longitudinal study on the scientists and engineers in the United States found that emigration rates were sizable, and emigrants were characterized by poor labor market outcomes. Borjas and Bratsberg (1996) have confirmed the importance of outmigration from the United States. They studied the experiences of foreign-born individuals and found that return migration intensifies the type of selection that generated the immigration flow in the first place. In the 1980's, emigration rates were lower than before but still varied substantially by nationality, ranging from $3.5 \%$ for Asians to $34.5 \%$ for North Americans (Borjas and Bratsberg, 1996).

Dustmann (1996) has demonstrated the relevance of return migration in the European context, where out-migration had been much higher than in the United States due to legal restrictions and migration policies. For Germany, the largest immigration country in Europe, Bohning (1981) has estimated that more than two thirds of the foreign workers admitted to the Federal Republic of Germany between 1961 and 1976 eventually 
returned home. The rates of return migration were particularly high for migrants from European Union countries, with 9 of 10 Italians, 8 of 10 Spaniards, and 7 of 10 Greeks ultimately going back. Those migrants who did not have the right to freely come and go returned in much smaller numbers. Over the same period, only 5 of 10 Yugoslavs and 3 of 10 Turks returned home. Constant and Massey (2003) documented an emigration rate of $18 \%$ for the guestworkers in Germany, and found that return migration probabilities are strongly determined by the range and nature of social and labor market attachments to Germany and origin countries. The odds of returning were the highest during the first five years since migration, grew higher toward retirement, and were high for remitters.

Once an out-migration has taken place, migrants are soon more prone to move again. The phenomenon of repeat migration has not been sufficiently studied. While there are some theoretical contributions to model this phenomenon, and there is some empirical research on repeat migration within the United States (an early example is DaVanzo, 1983), there is hardly any empirical evidence in the context of international migration. (See the overview introduction and the collected papers on repeat and return migration in Zimmermann and Bauer, 2002). An exception is the paper by Massey and Espinosa (1997), who established that Mexicans in the United States are indeed repeat migrants and showed that this phenomenon is even more common than return or onward migration. They found that repeat migration rises with prior experience in the United States, previous trips to the country, occupational achievements there, and is enhanced by the acquisition of migration-specific human capital. These results were stronger for documented than undocumented Mexicans, suggesting that holding legal documents facilitates repeat migration. Using count data models, Constant and Zimmermann (2003) demonstrated that immigrants in Germany are frequently moving out while returning later. 
Return migration might occur due to the (ex-post corrective) realization of suboptimal decisions or due to (ex-ante planning) predetermined intentions to return, and is, thus, viewed as a one-time event. Repeat migration - while it has the appearance of an indecisive perpetual move - might be a way of optimizing one's economic, social, and personal situation at every period as it might denote a preference for frequent locational changes in maximizing utility. Further, while the initial move to the host country is governed by uncertainty, repeat migration is operating under a complete information set.

In this paper we study the life-cycle probabilities of repeat migration. We conceptualize a repeat move as the move from the home country back to the host country, given that the initial move to the host country has taken place. We seek to identify the underlying factors that drive individuals to move in between countries. We determine how the transition probabilities vary over the life-cycle of an immigrant. In particular, does repeat migration occur mainly during the younger years or does it persist throughout the immigrant's life? We control for gender differences, human capital, country of origin, social capital, and employment characteristics. We further compare the immigrants who stayed in the host country, the stayers, with the repeats or those immigrants who move from one country to another and back, or chronic movers.

Our paper extends previous research on return migration by studying life-cycle events among both male and female immigrants, and by modeling repeated moves. To achieve these goals we undertake a detailed discrete time event history analysis using a Markovian framework and a logit specification in a novel research setting. Markov chains have been successfully used in other areas before (Katsinis and Constant, 1995). In this approach we model the probability of moving in and out of Germany at each point in time as a function of human capital, labor market characteristics, demographic traits, and social 
and psychological ties to places of origin and destination.

Our empirical analysis is based on data on the German immigrant experience from the first 14 years of the German Socio-Economic Panel (GSOEP). Our analysis suggests that over $60 \%$ of the immigrants in Germany, the guestworkers, are actually repeat migrants. On average, they exit from and return back to Germany at least once. Our analysis of 33,493 person years of information confirms that repeat migration is selective. The odds of repeating the move are highest for males while human capital does not seem to play a significant role. Immigrants who are attached to paid employment in Germany are less likely to repeat migration. On the other hand, remittances and familial reasons are the driving force of repeat migration. At the same time, we find that country of origin is very important with immigrants from other European Union countries being the most likely to repeat migration. While the average annual out-migration is at a low $10 \%$, the return probability is about $80 \%$ per year.

The rest of the paper is structured as follows: in Section II we outline the Markov modeling strategy of repeat migration and the empirical estimation of transition probabilities through logit models. In section III we present the data set, describe the construction of the variables employed, and explain the basic hypotheses for our empirical study. Section IV characterizes the sample used, and explains the econometric evidence. Lastly, Section V summarizes the paper and concludes.

\section{MODEL SPECIFICATION}

\section{A. A MARKOVIAN MODELING FRAMEWORK}

We model the movement of immigrants between Germany and the home country by a discrete-time discrete-space Markov process. We assume that the status of the immigrant 
at any period $t$ is described by a stochastic process $\left\{E_{t}\right\}$ that takes values in a finite discrete state space $S=\{0,1\}$. A Markov chain is a sequence of random values whose probabilities at a time interval depends upon the value of the number at the previous time (Papoulis, 1984). We embody the idea that if an individual knows the current state, it is only this current state that influences the probabilities of the future state. At each time, the Markov chain restarts anew using the current state as the new initial state. We assume that this Markov chain has two states, 0 and 1, indicating that an individual is in Germany and in the home country respectively. The vector containing the long-term probabilities, denoted by $\pi$, is called the steady-state vector of the Markov chain.

The state probability (row) vector is:

$$
\pi=\left[\begin{array}{ll}
\pi_{0} & \pi_{1}
\end{array}\right]
$$

where $\pi_{0}, \pi_{1}$ are the probabilities that a person is in Germany or in the home country. Under the assumption that the system converges and is in steady-state, the state probabilities do not depend on the year of observation. This is the stationary distribution of the chain and satisfies the equation

$$
\pi=\pi * \mathbf{P}
$$

where

$$
\mathbf{P}=\left(\begin{array}{ll}
\mathrm{p}_{0} & \mathrm{p}_{1} \\
\mathrm{p}_{2} & \mathrm{p}_{3}
\end{array}\right)
$$

is the transition probability matrix with $\mathrm{P}_{0}+\mathrm{P}_{1}=\mathrm{P}_{2}+\mathrm{P}_{3}=1$. Even if the system converges in the long run, the Markov chain equation does not need to hold in the short run. However, if this equation is closely applicable with real data this indicates that the Markov assumption 
is useful in describing reality. A transition probability is the commanding factor in a Markov chain. It is a conditional probability that the system will move to state 1 (or 0 ) in the next time period, given that it is currently in state 0 (or 1 ). The Markov chain obtains the much desired efficient estimates when the transition probabilities are properly determined.

The transition probabilities of an immigrant $m$ from one state to the other or to the same state depend only on the current state, and on the socioeconomic characteristics of the individual, $X_{m}$. These independent variables are expected to affect the individual's probability of being in a given state. Specifically, we consider four distinct outcomes: $P_{0}$ is the probability that an immigrant, who is in Germany in the current period, would tend to stay in Germany in the next period, while $P_{1}$ is the probability that an immigrant, who is in Germany in the current period, would tend to return to his home country in the next period. Similarly, $\mathrm{P}_{2}$ denotes the transition probability that an immigrant, who returned to his home country from Germany and who is currently in his home country, will return back to Germany in the next period, and $\mathrm{P}_{3}$ denotes the transition probability that an immigrant, who is currently in his home country will stay in the home country. Given the adding-up constraints $P_{0}=1-P_{1}$ and $P_{3}=1-P_{2}$, we need to model only $P_{1}$ and $P_{2}$.

We assume that individuals have a myopic foresight and they maximize their utility at every period given the state they are at currently. We assume a discrete time process where a person's status is a random process in time. The Markov approach is, then, an appropriate representation of the structure of the behavioral process of repeat migrants. The key feature of this model is that the future state depends solely on the current state.

\section{B. MODELING THE TRANSITION PROBABILITIES}

To estimate the transition probabilities $P_{1}$ and $P_{2}$ as they are explained by the 
characteristics, $\mathrm{X}$, of the individuals of the population under study we employ two binomial logits. The idea is that individuals have four choices but only two choices are effective at any time, depending on where they are located. When they are in Germany, the choice to go from their home country to Germany is conceptionally irrelevant. Therefore, we model their behavior separately, depending on which country they are in. In the first place, we estimate a logit on the probability to return to the home country or to stay in Germany, given that the immigrants live in Germany. Second, we estimate the probability to return to Germany from the home country or to stay in the home country, given that the immigrants have returned to the home country and live in the home country.

The closed form for the probability that a person will move from one state to the other from time $t$ to $t+1$ then is:

$$
P\left(E_{t+1}=i \mid E_{t}=j\right)=\frac{e^{\beta_{i j}^{\prime} X_{m t}}}{\sum_{k} e^{\beta_{i k}^{\prime} X_{m t}}} \quad i, j, k=1,2 \quad \forall t
$$

with $\beta_{11}=\beta_{22}=0, \beta_{12}=\beta_{1}$, and $\beta_{21}=\beta_{2}$. The characteristics in $X$ will help us explain how a person evolved into getting to that specific state and how his or her choice is influenced for the next move, whereas X may or may not be changing over time. Lastly, we calculate the steady probability vector $(\pi)$ to find the probability that an individual is in a certain state.

To sum-up: The Markov chain approach assumes that the transition probabilities are fixed. Then, any well-behaved empirical state probability vector converges quickly to its steady-state value to fulfill equation (2). However, at the level of the individual, the transition probabilities can be estimated using micro data. Hence, the Markov chain approach we are suggesting takes the estimated transition probabilities from equation (4) as predetermined for the next move. The pre-determined transition probabilities may evolve 
over time following the structure of the real population under study.

\section{DESCRIPTION OF THE DATA SET, VARIABLES, AND HYPOTHESES}

\section{A. The GSOEP}

The German Socioeconomic Panel (GSOEP), administered by DIW Berlin, is a nationally representative survey in Germany that started in 1984 in the former Federal Republic of Germany with a sample of about 12,000 respondents, 3,000 of whom were legal immigrants. The latter were those living in a household whose head was from Italy, Greece, Spain, Yugoslavia, or Turkey - the so-called guestworkers. The GSOEP is an ongoing longitudinal database that annually interviews all persons aged 16 or older. It contains rich socioeconomic information on both native Germans and legal immigrants. Since the 1990 reunification, the sample had broadened to incorporate all Germans - West and East. In 1996 the immigrant data base was expanded to include immigrants from other countries, especially eastern Europeans. The most important features of the GSOEP are that it oversamples guestworkers, and that it provides excellent information on their preimmigration experiences, their degree of socio-political integration into the German community, and documents actual return migration (SOEP Group, 2001).

The GSOEP is especially suited for analyzing emigration probabilities because it has a good record of following individuals who move within Germany, and a good record of tracking immigrants who returned back to Germany after they had gone to their homeland. Temporary drop-outs or persons who could not be successfully interviewed in a given year are followed until there are two consecutive temporary drop-outs of all household members or a final refusal. The longitudinal development of the database is influenced by demographic and field-related factors. 
The guestworker sample of the GSOEP forms the basis of our empirical analysis. Specifically, we consider the guestworker population in Germany during the period 19841997. Each year we exclude immigrants on active military duty because military personnel follow different moving trajectories and may skew our emigration estimates. There were only a dozen such exclusions over the entire panel. Our sample contains all individuals over 16 years of age who were successfully interviewed in a given year. This longitudinal sample contains 4,613 guestworkers, of whom 2,382 are men and 2,231 are women. Out of these migrants, we document 2,857 repeat migrants or migrants who have exited Germany at least once. They constitute $62 \%$ of the guestworker sample. Table 1 presents the yearly sample observations and the final longitudinal sample by gender.

\section{TABLE 1 ABOUT HERE}

To implement the event history analysis we restructured the GSOEP data into "person-years," which became the effective unit of our analysis. A person-year is a oneyear fraction of a person's life during which the event in question (a move to another country) may or may not occur. Each yearly fraction of a person's life is treated as a distinct observation. The person-year file contains information about the occurrence or nonoccurence of the event, as well as the values of relevant independent variables (with or without temporal variation); it is the life history of each person. However, it is not necessary that every person experiences the event.

The final person-year file has 33,493 observations, representing detailed longitudinal histories of immigrants' experiences and behavior from the moment immigrants entered the sample until emigration, death, or the final survey date. The variables we employ in our 
analysis may either be fixed or time-varying. The variables that change from year to year include age and years since first arrival. Those variables that are referring to fixed characteristics, such as gender, education before migration, and ethnicity, remain constant over person-years.

\section{B. VARIABLES AND HYPOTHESES}

Table 2 shows the construction and the coding of the dependent variable following the Markovian approach. The dependent variables in the logit specification are the transition probabilities $\mathrm{P}_{1}$ and $\mathrm{P}_{2}$. These transitions are distinct choices conditioned on the current state. Recall that by construction $\mathrm{P}_{0}=1-\mathrm{P}_{1}$ and $\mathrm{P}_{3}=1-\mathrm{P}_{2}$, since these are conditional probabilities. Therefore, it is sufficient in the sequel to model only $P_{1}$ and $P_{2}$. We implement this by coding two dummy variables which measure whether there was a repetitive move or not.

\section{TABLE 2 ABOUT HERE}

The transitions are driven by behavior based on individual characteristics and exogenous forces. Hence, a standard set of human capital and socioeconomic status (SES) measures are entered as covariates in the model. Our main interest is in how these characteristics influence individual migrants to make the transition from one state to the other. Human capital is captured by education, language, and exposure to Germany. The education variable includes both pre- and post-migration education. For education in Germany we consider three levels of education: (1) primary-secondary education, (2) higher education, and (3) no schooling in Germany, which is the omitted category. These 
levels denote terminal degrees. To capture the specificity of the German educational system we include vocational training as a separate variable, measuring whether the respondent has an apprenticeship training or a university degree. An apprenticeship training is a unique feature of Germany's educational system and an important part of formal education for non-university goers, who want to access skilled jobs. This is a better measure of human capital because in addition to formal education it includes the effect of training on occupational attainment. Vocational training defines the potentiality of a job.

In principle, according to the human capital theory, we expect that better educated individuals will be more mobile and will have a higher probability to migrate. However, this applies mostly to general education. Human capital specific to Germany may not be easily portable outside of Germany. Speaking the German language fluently not only facilitates every day transactions but it increases one's chances of finding a job and being integrated and accepted. We expect that immigrants who are fluent in German will be more likely to stay in Germany. However, speaking German can also be a valuable skill in the guestworker countries, especially countries that live out of tourism. Regarding the repeat migration decision, we expect that those immigrants who have been schooled and trained in Germany and who speak German fluently will be more likely to come back to Germany after they have emigrated to the home country.

Education in the home country is a continuous variable for the years of schooling and includes vocational training. We expect that those migrants who have been schooled and trained in their home country will have a higher probability to go back to their home country from Germany because they posses the necessary country specific skills and will go through a smoother adjustment upon return. Years since first arrival, the chief variable in all immigrant studies, is a continuous variable that captures the exposure to the German 
way of living and working. This variable encompasses knowledge about the labor market, the culture, the social conduct, and the institutions in a cumulative way. In theory, the more years one has spent in Germany the more likely one is to assimilate and integrate in Germany, and subsequently, to want to stay in Germany. At the same time, the longer years since first arrival can fade one's memory about the realities in the home country. We expect that longer years since first arrival will deter an immigrant from repeat migration. Put differently, the "newcomers" to Germany will have a higher probability to repeat migrate.

Having a job in Germany and the socioeconomic prestige of that job are two other determinants of repeat migration. They indicate attachment, integration, and success in the labor market. For the socioeconomic prestige of the job we use Treiman's international prestige scale that defines the actuality of the job. We expect that those immigrants who have a secured job in Germany will be less likely to repeat migration. For those immigrants who have managed to move up the socioeconomic ladder, as indicated by a higher Treiman score, we expect a higher likelihood of repeat. Higher ranking jobs render individuals more mobile because the dynamics of transferability are higher.

Remittances have been documented by the literature to be the driving force of migration, especially, of the guestworker type. The underlying motive is to work in Germany to earn money and to send money back home. Immigrants who remit money to their home country express a strong will to keep the bond with the home country alive and to go back to the home country. We expect to find that remittances will increase the likelihood of return migration from Germany, as they will increase the likelihood of returning back to Germany from the home country. Remittances will, thus, make immigrants more prone to repeat migration. Home ownership and German citizenship pertain to the determination and commitment one has to accept Germany as one's own country and to put down roots. For 
these two variables, we expect a negative correlation with the probability to go back to the home country from Germany, and a positive correlation with the probability to go back to Germany from the home country.

We employ marital status as another determinant of repeat migration. Here, we model being married or not (in Germany) and being married or not with the spouse living in the home country. Similarly, we distinguish between having young children in the household in Germany, and having children in the home country. We conjecture that the immigrants who have left their spouses and children in the home country will be more likely to be repeat migrants. This suggests that these individuals are more economic migrants, who go abroad to work and earn money to take care of their household in their home country.

We lastly consider the country of origin impact. We hypothesize that immigrants from different countries of origin will exhibit different repeat migration patterns. We classify immigrants from Greece, Italy, and Spain as European Union nationals, and we separate them from Turks and ex-Yugoslavs. Specifically, we expect that immigrants from European Union countries will have a higher likelihood to repeat migration between Germany and the home country because of the free labor movement within the European Union countries. European Union nationals can choose a country and can find a job easier. In contrast, Turks and nationals from the former Yugoslavia should have a lower probability to repeat migration because their re-entry into Germany is not unfettered.

\section{EMPIRICAL FINDINGS}

\section{A. CHARACTERISTICS OF THE SAMPLE POPULATION}

Table 3 presents the selected sample characteristics from the year before the immigrants 
undertook their first repeat move. These summary statistics are based on the panel data set and are calculated separately for the immigrants who did not leave Germany to go back to their home countries, the stayers, and for the immigrants who left Germany at least once throughout the panel, the repeats. A repeat move is defined as a move from Germany to the home country and back into Germany.

\section{TABLE 3 ABOUT HERE}

The average repeat migrant in our sample has at least one repeat move and has been in the panel for half the time as the average stayer. Comparing the repeats to the stayers we see that there are differences with respect to age, education, labor market attachment, remittances, home ownership, marital and citizenship status. In effect, we find that the average repeat migrant is older than the average stayer. When we look into specific age groups, we find that a much higher percentage of the repeats are in the 25-64 and over 65 age groups. Regarding their education acquired in Germany, a larger percentage of the repeat migrants never went to school in Germany and a smaller percentage of them has invested in higher education, compared to the stayers. In fact, repeat migrants are by $53 \%$ less in the higher education category, and are less fluent in German by $18 \%$.

These raw statistics also point to a difference in labor market attachment. It is interesting that repeat migrants exhibit a stronger commitment to the labor market, i.e. they are more likely to be labor migrants. A larger percentage of the repeat migrants are working full time in Germany (49\% as opposed to $44 \%$ among the stayers) and a lower percentage of them are unemployed. However, they rank at the same occupational prestige scale as 
the stayers. Almost a quarter of the repeat migrants remit money to their home country, a much larger percentage than the stayers. This shows that repeat migrants keep strong ties to the country of origin. Repeat migrants also exhibit a lower interest in acquiring the German citizenship, and in acquiring wealth in Germany as indicated by home ownership.

Further, not only a higher percentage of the repeats are married, but a higher percentage of them have a spouse in the home country. Naturally, a higher percentage of the repeats also have children in the home country. This further suggests that repeat migrants have managed to maintain a strong kinship link throughout their immigrant career in Germany. For the time being, these migrants tend to treat Germany as the country of employment and their home country as the country of having a "home" and a family. However, it is unclear and open to study how this family component evolves over time. Is Germany becoming also the "home" country after time passes and the family follows the migrant, or is the migrant finally returning home from Germany? The key question is whether the absorbing state is Germany or the country of origin.

Lastly, the overwhelming majority of the repeat migrants are from the European Union, namely Italy, Greece, and Spain. In contrast, nationals from the former Yugoslavia are less likely to be in the repeats category ( $14 \%$ versus $18 \%$ among the stayers).

In general, these characteristics show that although the immigrants who repeatedly cross the borders are more likely to be employed and, indeed full-time employed, they do not feel attached to the German sociocultural society, while they have maintained strong ties with the countries of origin.

In Table 4 we present the transition probabilities calculated experimentally from the raw data. This table shows that the transition probabilities are $P_{1}=0.096$ and $P_{2}=0.844$. Clearly, the probability to make the transition from Germany to the home country, $P_{1}$, is at 
a low $10 \%$ while the probability to make the transition from the home country to Germany, $\mathrm{P}_{2}$, is at a high $80 \%$ in the sample average. Further, from the raw data we calculated the average initial state distribution vector as $\pi=\left[\begin{array}{ll}\pi_{0} & \pi_{1}\end{array}\right]=\left[\begin{array}{ll}0.979 & 0.021\end{array}\right]$. Applying the Markov chain equation the calculated estimates of the steady state probabilities after the transition are: $\pi^{*}=\left[\begin{array}{ll}0.902 & 0.098\end{array}\right]$; this is nothing else than the average state probabilities from the raw data after the transition. These numbers are sufficiently close to $\pi$ to make us believe that the Markov chain specification is an appropriate representation for our repeat migration setting.

\section{TABLE 4 ABOUT HERE}

\section{B. ESTIMATION RESULTS}

In Table 5 we present the results on the transition probabilities conditioned on the current state. In the first column $\left(\mathrm{P}_{1}\right)$ we present the log-odds of choosing to go to the home country as opposed to choosing to stay in Germany, and the odds ratios of that choice. The second column $\left(\mathrm{P}_{2}\right)$ pertains to the current state being in the home country. Here we present the log-odds of choosing to go back to Germany as opposed to choosing to stay in the home country, and the odds ratios of that choice. Standard errors are reported underneath the coefficients and the asterisk denotes a $5 \%$ significance from a one-sided test. In the following we concentrate our discussion around the statistically significant coefficients. 
With regards to returning to the home country from Germany $\left(P_{1}\right)$ we find that the constant term is negative and significant, suggesting that this probability is very low. Male immigrants are $9 \%$ more likely to return than female immigrants. The age coefficients indicate that the odds of returning are a negative, albeit increasing function of age in the empirically relevant range. Figure 1 portrays the probability of returning to the home country from Germany $\left(P_{1}\right)$ as a function of age. This probability is evaluated at the average level of all other characteristics. The curve $P_{1}$ is almost flat hovering around a level of less than $10 \%$.

\section{FIGURE 1 ABOUT HERE}

Similarly, we find that the odds of returning decrease with additional years since first arrival but at an increasing rate. In Figure 2 we plot the probability of returning to the home country as a function of years since first arrival. These probabilities are evaluated at the means of all the other variables. Clearly, the probability to return to the home country from Germany $\left(P_{1}\right)$ is very low. The probability to return is the highest in the beginning of the immigrants' arrival in Germany and then it decreases until about 40 years since first arrival. Afterwards it stabilizes and remains constant.

\section{FIGURE 2 ABOUT HERE}

Table 5 further shows that human capital acquired in Germany has only limited explanatory power. The various school levels, that we considered, are not significant predictors on the odds of returning. The coefficient estimate of vocational training is 
significant and shows that those who have acquired vocational training in Germany have an $11 \%$ higher tendency to return, compared to those who do not have any vocational training in Germany. This finding suggests that vocational training is a valuable asset for immigrants that renders them more marketable. It is also more portable and more likely to be rewarded at both countries. German language fluency is significant and, as expected, those immigrants who speak it fluently, are less likely to return.

A strong determinant of the odds of returning home is whether immigrants are employed in Germany or not. We find that the odds of returning, for those who have a job in Germany, are $20 \%$ lower than for those who do not have a job. Ethnicity also has a differential effect, with Turks and ex-Yugoslavs exhibiting lower tendencies to leave, compared to European Union nationals. Next, we find that married immigrants are less likely to leave Germany. However, when their spouse is left in the home country immigrants have a higher probability to return by $72 \%$. Likewise, when they have children in the home country they have a higher probability to return by $45 \%$.

Overall, repeat migrants are more likely to leave Germany in the beginning of their immigrant career, when they have acquired vocational training in Germany, and when they have close social and familial bonds in the home country. On the other hand, they are less likely to leave Germany when they have a job in Germany, they speak the language well, and are married. Among all immigrant groups, Turks and Yugoslavs are less likely to undertake a repeat move.

The last column of Table $4\left(\mathrm{P}_{2}\right)$ shows a significantly high intercept term. The quadratic specification of the age variable is significant and denotes a convex shape. Immigrants who are in their home country are less likely to go back to Germany with each additional year when they are younger. However, $\mathrm{P}_{2}$ increases as they get older. This $\mathrm{U}$ - 
shape of the immigrants' probability to return back to Germany from home - evaluated at the average level of the rest of the variables - is plotted against age again in Figure 1. Considering the relevant range of age between 16 and 60 , this figure shows that the probability $\mathrm{P}_{2}$ is quite high when the immigrants are young (around 20 years of age) but it first decreases at a decreasing rate as they get older. The probability to return to Germany from home reaches a minimum around 35 years of age and then it increases steadily. This suggests that repeat migration occurs mostly after 35 years of age. The evolvement of the transition probabilities with increasing age suggests that the absorbing state is rather Germany than the sending country.

In Figure 2 we also plot the probability of returning back to Germany $\left(P_{2}\right)$ from the home country as a function of years since first arrival. ${ }^{1}$ This probability is evaluated at the means of all the other variables. This graph is almost a mirror image of the probability of going back to the home country $\left(\mathrm{P}_{1}\right)$ also included in Figure 2 . The probability to go back to Germany with additional years since first arrival is very high but has a rather flat curvature. The evolvement of the transition probabilities with increasing years since first migration suggests that the absorbing state is rather Germany than the sending country.

The rest of the results in Table 5 show that immigrants who have finished primary or secondary education in Germany are less likely to move back to Germany, compared to those who have no degree in Germany. Our explanation is that, because this is a very low level of education it does not substantially help them in faring well in Germany. However, the odds of going back to Germany from the home country for those who have

\footnotetext{
${ }^{1}$ Whereas the years since first arrival variable is not statistically significant, we find that this variable has an economic significance and it enlightens the repeat migration behavior of immigrants.
} 
acquired vocational training in Germany are $74 \%$ higher, compared to those immigrants who have not had vocational training in Germany. From this estimate and the respective estimate in $\mathrm{P}_{1}$ we conclude that vocational training in Germany is useable and functional in both the host and home countries. Vocational training is a rather practical but valuable education that is highly associated with labor market skills that are in demand. It is readily transferable and goes to the heart of the accessibility to jobs. We find that this training is positively correlated to repeat migration.

As expected, we find that the immigrants who remit are significantly more likely to go back to Germany from their home country. Compared to those who do not remit, the odds of going back to Germany are two and a half times higher. This finding suggests that repeat migrants may be using Germany as the country where they can work and earn money. Among all immigrants, the ex-Yugoslavs are less likely than the European Union nationals to return back to Germany once they have been in their home country.

A puzzle remains with the German passport variable. We find that, among all immigrants, those who have the German passport are less likely to go back to Germany once they are in their home country. Becoming a German citizen is not based on merit or special talents directly related to the labor market. As we saw from the results on $P_{1}$, the German passport is not a significant determinant of the transition to the home country. We conjecture that because (I) repeat immigrants are labor migrants and (ii) German citizenship is not necessarily linked to the labor market, it can be a deterrent from going back to Germany.

Understandably, we find that the immigrants who are married and their spouse lives in the home country, are less likely to repeat the move and come back to Germany in a particular period. However, the odds of returning to Germany from the home country are 
3.6 times higher for those immigrants who are married with a spouse in Germany. Likewise, those with under age kids in the household are more likely to return back to Germany by $66 \%$. These results suggest strong familial dynamics. In sum, the immigrants who choose to come back to Germany and repeat their migration pattern are guided by the motive to remit, by strong familial considerations, and is facilitated by investment vocational training.

Our analysis so far suggests that for the current stock of migrants from the sending countries of the guestworker generation the final absorbing state is very likely to be Germany and not the country of origin. We examine this by simulating a hypothetical lifecycle of a sample average unmarried and a married individual who immigrated to Germany for the first time at the age of 20 and has no children. The simulated return and repeat probabilities $P_{1}$ and $P_{2}$ for both types of individuals are graphed against time for nonmarried migrants in Figure 3 and for married migrants in Figure 4.

\section{FIGURE 3 ABOUT HERE}

In Figure 3 we first trace the transition probability of going home to the home country as a function of time for a non-married individual. Overall, the probability to move out of Germany $\left(P_{1}\right)$ is low. However, this probability is the highest in the beginning of time, and decreases up to 30 years, where it stabilizes and stays at below $10 \%$. This graph is very similar to the return probability $\left(\mathrm{P}_{1}\right)$ in Figure 2, indicating that years since first arrival has the strongest effect in the transition probability of going out of Germany.

Figure 3 also depicts the transition probability of going back to Germany from home $\left(P_{2}\right)$ as a function of time. It shows a pronounced convex curvature. It is high, compared 
to $P_{1}$ in the same figure, starting at $80 \%$, and decreases steadily as time passes during the first 15 years to reach its minimum. It, then, increases steeply approaching 1 . This figure is very similar to $P_{2}$ in Figure 1. It shows that when one is in his home country the transition probability of going back to Germany is largely guided by the age variable.

Figure 4 replicates the simulation exercise of Figure 3 for a married average individual. The basic structure is the same, but with some marked differences. Non-married immigrants are more likely to go home and stay longer home (their repeat migration probability is much lower) than married individuals at lower ages. This suggests that the move home of non-married individuals serves the purpose to find a spouse at home. However, with time passing, the repeat probabilities $P_{2}$ strongly grow and approach 1 for both married and non-married individuals. Hence, while some low constant outflow of about $10 \%$ per period takes place, there is a strong return probability to Germany as the absorbing state. Hence, contrary to general belief, the migrant population in Germany studied here does not seem to finally move back home.

\section{FIGURE 4 ABOUT HERE}

\section{SUMMARY AND CONCLUSIONS}

In this paper we studied the behavior of immigrants who repeat their migration moves between the host and home country. Assuming a discrete time and space process where the status of a person is a random process in time, a Markov chain is an appropriate representation of the structure of the behavioral process of repeat migrants. The key feature of this model is that the future state depends solely on the current state. Empirically, we estimated the transition probabilities through two binomial logits, 
conditioned on whether one is in Germany or in the home country explained through various characteristics.

Based on 14 years of longitudinal data from the GSOEP, we estimated the repeat migration probabilities for the guestworkers by implementing a person-year structure. Our study shows that more than $60 \%$ of the migrants in Germany are indeed repeat migrants. Whereas male immigrants are $9 \%$ more likely to return to their home country than female immigrants, gender is not significant for the repeat move back to Germany. The probability of repeating the migration move is high and decreases when one is young up to 35 years of age. The probability of repeating the migration move becomes an increasing function of age thereafter. Overall, repeat migrants are more likely to leave Germany in the beginning of their immigrant career, when they have acquired vocational training in Germany, and when they have social and familial bonds in their home country. On the other hand, they are less likely to leave Germany when they have a job in Germany, they speak the language well, and are married.

Among all immigrant groups, Turks and Yugoslavs are less likely to undertake a repeat move compared to European Union nationals. The immigrants who choose to come back to Germany and repeat their migration pattern are, however, mainly guided by remittances and family considerations. Vocational training, a special feature of Germany's educational system, is highly and positively correlated to the odds of repeating the migration move. This valuable training is more portable in the migrants' own countries and makes them more marketable. The odds of returning to the home country from Germany and the odds of going back to Germany from the home country as a function of vocational training are 11 and $74 \%$ respectively, everything else held constant.

In sum, immigrants' probabilities to leave Germany are low, about $10 \%$, but once 
they are in their home country the probabilities of undertaking a repeat move - by returning back to Germany - are high, about $80 \%$ in the average of the observed transition situations. Simulations with our estimated models have shown that while the probability to return home remains low as time passes, the probability of return back to Germany from the home country approaches 1 the older immigrants are and the earlier they have migrated for the first time to Germany. Our results point to the fact that repeat migrants are indeed labor migrants, who go to Germany to work and earn money, and that there is no evidence that they finally attempt to return to the home country. To the contrary, Germany remains a magnet for these immigrants. Future research should study this closer. It also should examine the family dynamics and model the repeat migration process as a joint family decision. 


\section{REFERENCES}

Borjas, George J., "Immigrant and Emigrant Earnings: A Longitudinal Study," Economic Inquiry 27 (1989), 21-37.

Borjas, George, and Bernt Bratsberg, "Who Leaves? The Outmigration of the ForeignBorn," The Review of Economics and Statistics 78 (1996), 165-176.

Constant, Amelie, and Douglas S. Massey, "Self-Selection, Earnings, and Out-Migration: A Longitudinal Study of Immigrants to Germany," Journal of Population Economics 16 (2003).

Constant, Amelie, and Klaus F. Zimmermann, "Circular Movements and Time Away from the Host Country," mimeo, IZA, Bonn, (2003).

DaVanzo, Julie, "Repeat Migration in the United States: Who Moves Back and Who Moves On?," The Review of Economics and Statistics 65 (1983), 552-559.

Dustmann, Christian, "Return Migration: The European Experience," Economic Policy 22 (1996), 214-250.

Jasso, Guilermina, and Mark R. Rosenzweig,"Estimating the Emigration Rates of Legal Immigrants Using Administrative and Survey Data: The 1971 Cohort of Immigrants to the United States," Demography 19 (1982), 279-290.

Jasso, Guilermina, and Mark R. Rosenzweig, The New Chosen People: Immigrants in the United States (New York: Russell Sage Foundation, 1990).

Katsinis, Constantine, and Amelie Constant, "Bandwidth Allocation in Wideband Communication Networks under Two Types of Priorities," The Computer Communications Journal 18 (1995), 657-662.

Massey, Douglas S., and Karen E. Espinosa, "What's Driving Mexico-U.S. Migration? A Theoretical, Empirical, and Policy Analysis," American Journal of Sociology, 102 (1997), 939-999.

Papoulis, Athanasios, Probability, Random Variables, and Stochastic Processes, (New York: McGraw-Hill, 1984).

Soep Group (2001) The German Socio-Economic Panel (GSOEP) after more than 15 years - Overview. In: Elke Host, Dean R. Lillard, and Thomas A DiPrete (eds): Proceedings of the 2000 Fourth International Conferences of German Socio-Economic Panel Study Users (GSOEP2000), Quarterly Journal of Economic 
Research, Vol. 70, No. 1, 7-14.

Warren, Robert, and Jennifer Marks Peck, "Foreign-Born Emigration from the United States: 1960-1970," Demography 17 (1980), 71-84.

Warren, Robert, and Ellen Percy Kraly, "The Elusive Exodus: Emigration from the United States," Population Trends and Public Policy 7 (1987).

Zimmermann, Klaus F., and Thomas Bauer, The Economics of Migration, Vol. I, The Migration Decision and Immigration Policy, (Cheltenham, UK: Edward Elgar, 2002). 
TABLE 1. YEARLY OBSERVATIONS BY GENDER

\begin{tabular}{|c|c|c|c|c|}
\hline WAVE & YEAR & $\begin{array}{c}\text { MALES } \\
(1)\end{array}$ & $\begin{array}{c}\text { FEMALES } \\
\text { (2) }\end{array}$ & $\begin{array}{c}\text { TOTAL } \\
(3) \\
\end{array}$ \\
\hline 1 & 1984 & 1,592 & 1,418 & 3,010 \\
\hline 2 & 1985 & 1,375 & 1,226 & 2,601 \\
\hline 3 & 1986 & 1,349 & 1,180 & 2,529 \\
\hline 4 & 1987 & 1,345 & 1,197 & 2,542 \\
\hline 5 & 1988 & 1,275 & 1,160 & 2,435 \\
\hline 6 & 1989 & 1,237 & 1,167 & 2,404 \\
\hline 7 & 1990 & 1,242 & 1,145 & 2,387 \\
\hline 8 & 1991 & 1,241 & 1,148 & 2,389 \\
\hline 9 & 1992 & 1,224 & 1,148 & 2,372 \\
\hline 10 & 1993 & 1,220 & 1,139 & 2,359 \\
\hline 11 & 1994 & 1,158 & 1,110 & 2,268 \\
\hline 12 & 1995 & 1,089 & 1,053 & 2,142 \\
\hline 13 & 1996 & 1,043 & 1,018 & 2,061 \\
\hline 14 & 1997 & 1,015 & 979 & 1,994 \\
\hline \multicolumn{2}{|c|}{ All 14 Waves (individuals) } & 2,382 & 2,231 & 4,613 \\
\hline \multicolumn{2}{|c|}{ Repeat migrants } & & & $2,857(62 \%)$ \\
\hline \multicolumn{2}{|c|}{ Person Year Observations } & 17,405 & 16,088 & 33,493 \\
\hline
\end{tabular}

Source: Own calculations from GSOEP 1984-1997 
TABLE 2: TRANSITION PROBABILITIES CATEGORIES

\begin{tabular}{l|l|l}
\hline Current State & Constructed Dependent Variable & Meaning \\
\hline \multirow{3}{*}{ In Germany } & TRANSITION (0), $\mathrm{P}_{0}$ & Probability of staying in Germany \\
\cline { 2 - 3 } & TRANSITION (1), $\mathrm{P}_{1}$ & Probability of going out to the home country \\
\hline \multirow{2}{*}{ In Home Country } & TRANSITION (2), $\mathrm{P}_{2}$ & Probability of returning back to Germany \\
\cline { 2 - 3 } & TRANSITION (3), $\mathrm{P}_{3}$ & Probability of staying in the home country \\
\hline
\end{tabular}


TABLE 3: SELECTED SAMPLE CHARACTERISTICS BEFORE THE FIRST REPEAT MOVE

\begin{tabular}{|c|c|c|c|c|}
\hline \multirow[b]{2}{*}{ Characteristics } & \multicolumn{2}{|c|}{ Repeat Migrants } & \multicolumn{2}{|c|}{ Stayers } \\
\hline & Mean & Std.Dev. & Mean & Std.Dev. \\
\hline Number of repeat moves & 1.130 & 0.372 & 0 & 0 \\
\hline Time in the Panel (in years) & 5.686 & 4.191 & 10.232 & 4.602 \\
\hline Male & $52.30 \%$ & 0.500 & $50.50 \%$ & 0.500 \\
\hline Age in years & 32.888 & 13.579 & 29.351 & 12.026 \\
\hline Age (16-18) & $20.30 \%$ & 0.403 & $28.50 \%$ & 0.452 \\
\hline Age (19-24) & $16.80 \%$ & 0.374 & $18.20 \%$ & 0.386 \\
\hline Age (25-64) & $62.20 \%$ & 0.485 & $53.10 \%$ & 0.499 \\
\hline Age $(65+)$ & $0.60 \%$ & 0.077 & $0.20 \%$ & 0.041 \\
\hline Years Since First Arrival & 14.474 & 7.467 & 14.522 & 8.295 \\
\hline No School Degree in Germany & $74.70 \%$ & 0.435 & $68.30 \%$ & 0.466 \\
\hline Primary-Secondary Education in Germany & $18.10 \%$ & 0.385 & $16.50 \%$ & 0.371 \\
\hline Higher Education in Germany & $7.20 \%$ & 0.259 & $15.20 \%$ & 0.359 \\
\hline Vocational Training in Germany & $16.80 \%$ & 0.374 & $16.20 \%$ & 0.369 \\
\hline Speaking German Fluently & $19.30 \%$ & 0.395 & $23.60 \%$ & 0.425 \\
\hline Years of Education in Native Country & 4.699 & 3.485 & 4.099 & 3.738 \\
\hline Employed & $59.70 \%$ & 0.491 & $54.60 \%$ & 0.498 \\
\hline Employed Full-time & $49.20 \%$ & 0.500 & $44.00 \%$ & 0.497 \\
\hline Not Employed & $34.30 \%$ & 0.475 & $40.20 \%$ & 0.490 \\
\hline Prestige of Job in Germany (Treiman Scale) & 31.893 & 11.156 & 31.371 & 11.533 \\
\hline Remit to Native Country & $23.90 \%$ & 0.427 & $18.00 \%$ & 0.384 \\
\hline Home Ownership in Germany & $5.90 \%$ & 0.235 & $8.80 \%$ & 0.284 \\
\hline German Citizen & $13.10 \%$ & 0.337 & $21.60 \%$ & 0.412 \\
\hline Turk & $32.10 \%$ & 0.467 & $33.00 \%$ & 0.470 \\
\hline ex-Yugoslav & $14.00 \%$ & 0.347 & $18.20 \%$ & 0.386 \\
\hline European Union Citizen & $40.80 \%$ & 0.492 & $27.20 \%$ & 0.445 \\
\hline Married & $63.00 \%$ & 0.483 & $58.10 \%$ & 0.493 \\
\hline Married Spouse not in Germany & $3.50 \%$ & 0.183 & $1.80 \%$ & 0.134 \\
\hline Children $<16$ years old in the Household & $60.80 \%$ & 0.488 & $60.10 \%$ & 0.490 \\
\hline Children in Native Country & $7.80 \%$ & 0.268 & $5.80 \%$ & 0.234 \\
\hline Feel Mostly German & $3.50 \%$ & 0.183 & $3.40 \%$ & 0.180 \\
\hline Observations & & & & \\
\hline
\end{tabular}

Source: Own calculations from GSOEP 1984-1997 
TABLE 4 : CALCULATED TRANSITION PROBABILITIES MATRIX

\begin{tabular}{l|c|c}
\hline \multicolumn{2}{c}{ STATE $(\mathrm{t}+1)$} \\
\hline STATE $(\mathrm{t})$ & IN GERMANY & IN HOME COUNTRY \\
\hline IN GERMANY & 0.904 & 0.096 \\
\hline IN HOME COUNTRY & 0.844 & 0.156 \\
\hline
\end{tabular}


TABLE 5: REPEAT MIGRATION: LOGIT RESULTS

\begin{tabular}{|c|c|c|c|c|}
\hline \multirow[b]{2}{*}{ VARIABLES } & \multicolumn{4}{|c|}{$\begin{array}{l}\text { Probability to Return to Home Country Probability to Return Back to Germany } \\
\qquad\left(\mathrm{P}_{1}\right)\end{array}$} \\
\hline & Coefficient & Odds Ratio & Coefficient & Odds Ratio \\
\hline$\overline{\text { Constant }}$ & $\begin{array}{l}-1.113^{*} \\
(0.183)\end{array}$ & - & $\begin{array}{l}3.089^{*} \\
(1.395)\end{array}$ & - \\
\hline Male & $\begin{array}{l}0.086^{*} \\
(0.041)\end{array}$ & 1.090 & $\begin{array}{l}0.415 \\
(0.256)\end{array}$ & 1.514 \\
\hline Age & $\begin{array}{l}-0.011 \\
(0.010)\end{array}$ & 0.989 & $\begin{array}{l}-0.147 \\
(0.090)\end{array}$ & 0.863 \\
\hline Age Squared & $\begin{array}{l}0.0002^{*} \\
(0.0001)\end{array}$ & 1.000 & $\begin{array}{l}0.002^{*} \\
(0.001)\end{array}$ & 1.002 \\
\hline Years since first Arrival & $\begin{array}{l}-0.037^{*} \\
(0.007)\end{array}$ & 0.964 & $\begin{array}{l}-0.019 \\
(0.052)\end{array}$ & 0.981 \\
\hline Years since first Arrival Squared & $\begin{array}{l}0.0004^{*} \\
(0.0001)\end{array}$ & 1.000 & $\begin{array}{l}0.0004 \\
(0.001)\end{array}$ & 1.000 \\
\hline Education in Home Country & $\begin{array}{l}-0.006 \\
(0.007)\end{array}$ & 0.994 & $\begin{array}{l}-0.004 \\
(0.052)\end{array}$ & 0.996 \\
\hline Primary-Secondary Education in G & $\begin{array}{c}0.073 \\
(0.063)\end{array}$ & 1.076 & $\begin{array}{l}-0.567^{*} \\
(0.311)\end{array}$ & 0.567 \\
\hline Higher Education in Germany & $\begin{array}{l}-0.005 \\
(0.076)\end{array}$ & 0.996 & $\begin{array}{l}-0.429 \\
(0.437)\end{array}$ & 0.651 \\
\hline Vocational Training in Germany & $\begin{array}{l}0.102^{*} \\
(0.058)\end{array}$ & 1.108 & $\begin{array}{l}0.551^{*} \\
(0.316)\end{array}$ & 1.735 \\
\hline Speaking German Fluently & $\begin{array}{l}-0.115^{\star} \\
(0.054)\end{array}$ & 0.892 & $\begin{array}{l}-0.304 \\
(0.283)\end{array}$ & 0.738 \\
\hline Employed in Germany & $\begin{array}{l}-0.227^{*} \\
(0.044)\end{array}$ & 0.797 & $\begin{array}{c}0.217 \\
(0.270)\end{array}$ & 1.242 \\
\hline Prestige of Job in Germany & $\begin{array}{l}-0.001 \\
(0.002)\end{array}$ & 0.999 & $\begin{array}{c}0.014 \\
(0.011)\end{array}$ & 1.014 \\
\hline Remit to Home Country & $\begin{array}{c}0.052 \\
(0.051)\end{array}$ & 1.054 & $\begin{array}{l}0.908^{*} \\
(0.505)\end{array}$ & 2.479 \\
\hline Home Ownership in Germany & $\begin{array}{l}-0.053 \\
(0.065)\end{array}$ & 0.948 & $\begin{array}{l}-0.133 \\
(0.355)\end{array}$ & 0.875 \\
\hline German Citizen & $\begin{array}{l}-0.002 \\
(0.071)\end{array}$ & 0.998 & $\begin{array}{l}-0.653^{*} \\
(0.375)\end{array}$ & 0.520 \\
\hline Turk & $\begin{array}{l}-0.322^{*} \\
(0.047)\end{array}$ & 0.724 & $\begin{array}{l}-0.423 \\
(0.356)\end{array}$ & 0.655 \\
\hline Ex-Yugoslav & $\begin{array}{l}-0.447^{*} \\
(0.059)\end{array}$ & 0.640 & $\begin{array}{l}-1.025^{\star} \\
(0.378)\end{array}$ & 0.359 \\
\hline Married & $\begin{array}{l}-0.322^{*} \\
(0.055)\end{array}$ & 0.724 & $\begin{array}{l}1.286^{*} \\
(0.359)\end{array}$ & 3.619 \\
\hline Married Spouse Not in Germany & $\begin{array}{l}0.542^{*} \\
(0.109)\end{array}$ & 1.719 & $\begin{array}{l}-1.813^{*} \\
(0.752)\end{array}$ & 0.163 \\
\hline Kids $<16$ Year Old in Household & $\begin{array}{c}0.011 \\
(0.042)\end{array}$ & 1.011 & $\begin{array}{l}0.505^{*} \\
(0.259)\end{array}$ & 1.658 \\
\hline Kids in Native Country & $\begin{array}{l}0.372^{*} \\
(0.078)\end{array}$ & 1.450 & $\begin{array}{c}1.574 \\
(1.100)\end{array}$ & 4.824 \\
\hline $\begin{array}{l}\text { Log likelihood } \\
\text { Chi squared } \\
\text { Number of Observations }\end{array}$ & & & & \\
\hline
\end{tabular}




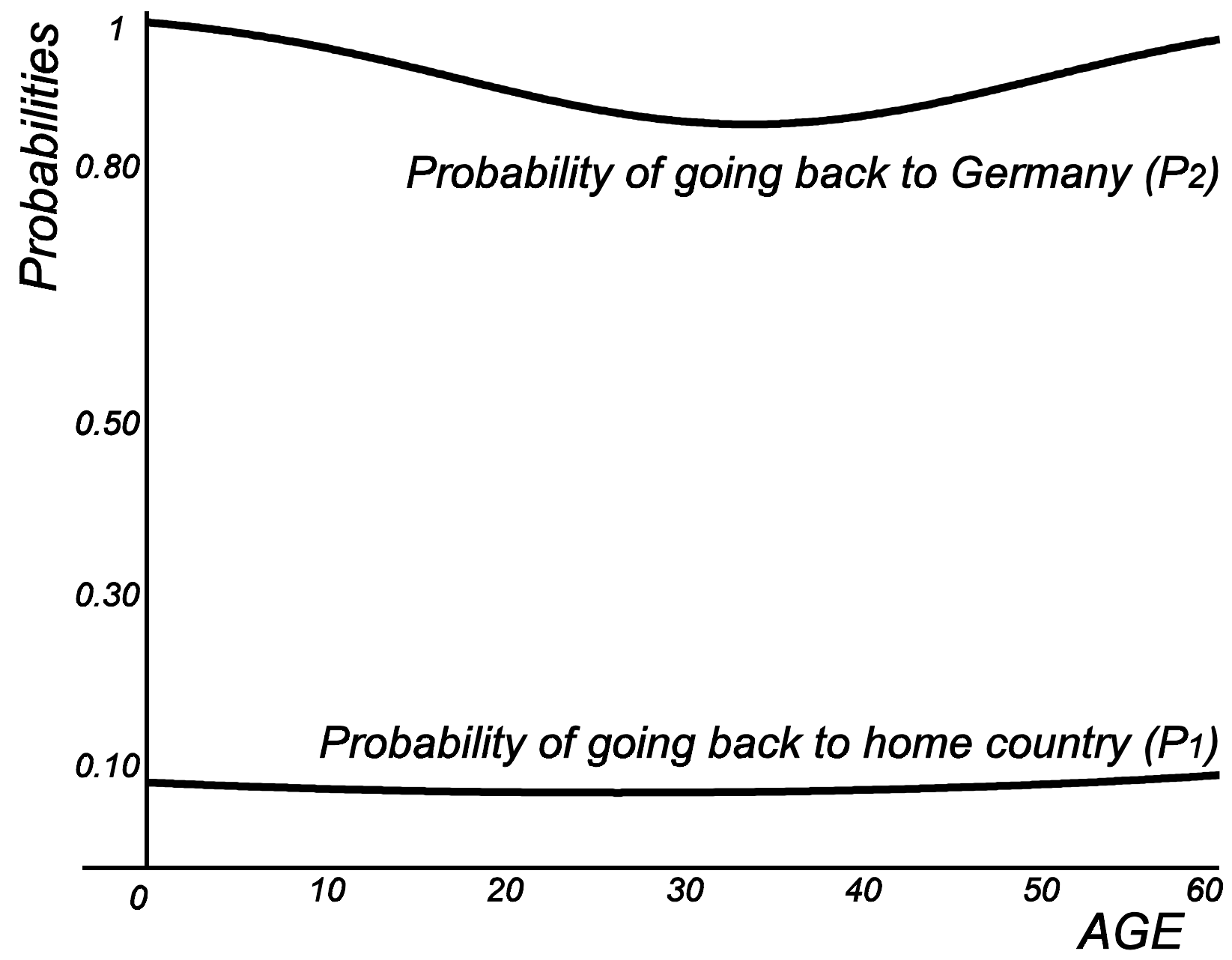

Figure 1: TRANSITION PROBABILITIES BY AGE

NOTE: $P_{1}$ and $P_{2}$ are conditional probabilities from different states and do not add up to one (see Table 2). 


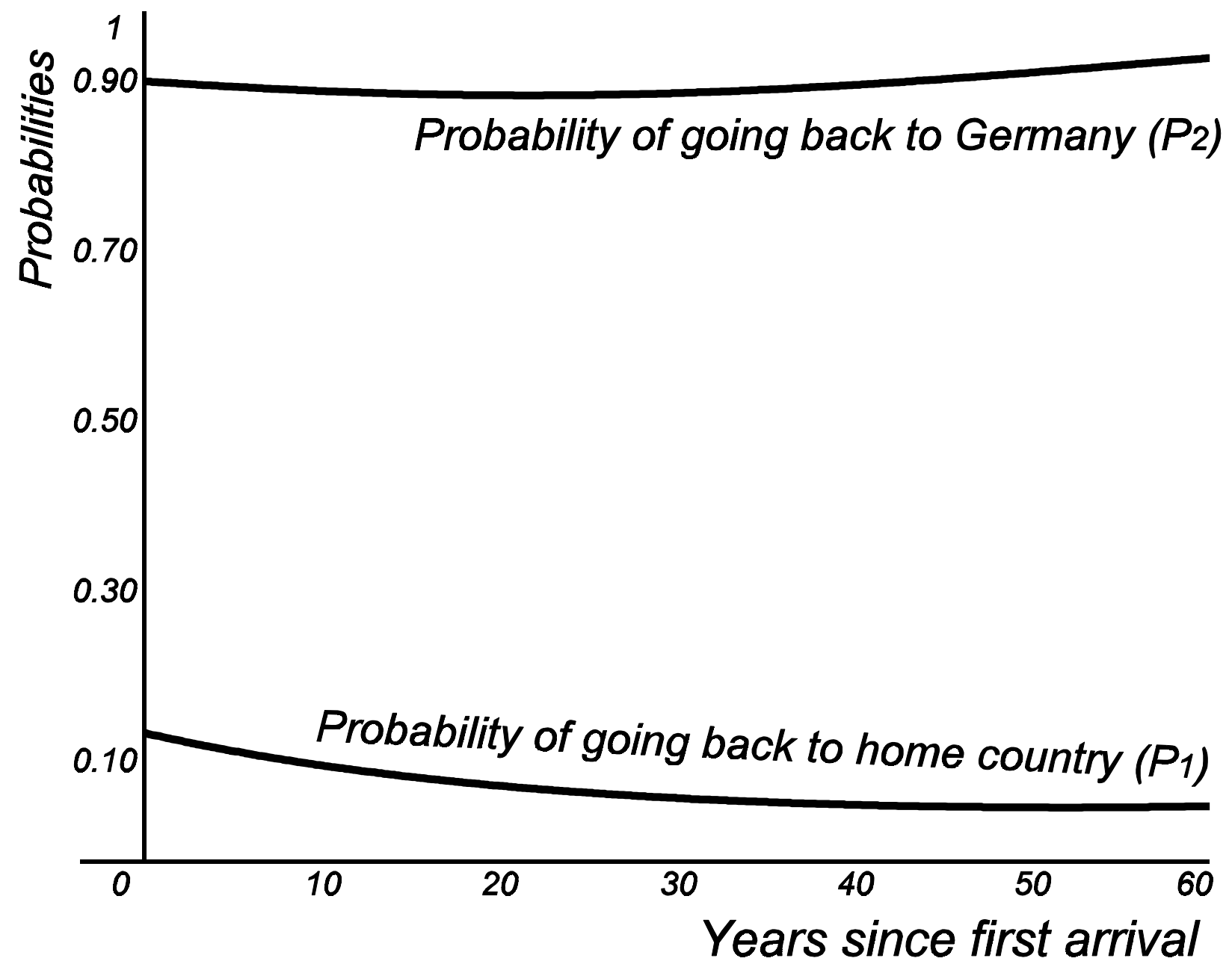

Figure 2: TRANSITION PROBABILITIES BY YEARS SINCE FIRST ARRIVAL

NOTE: $P_{1}$ and $P_{2}$ are conditional probabilities from different states and do not add up to one (see Table 2). 


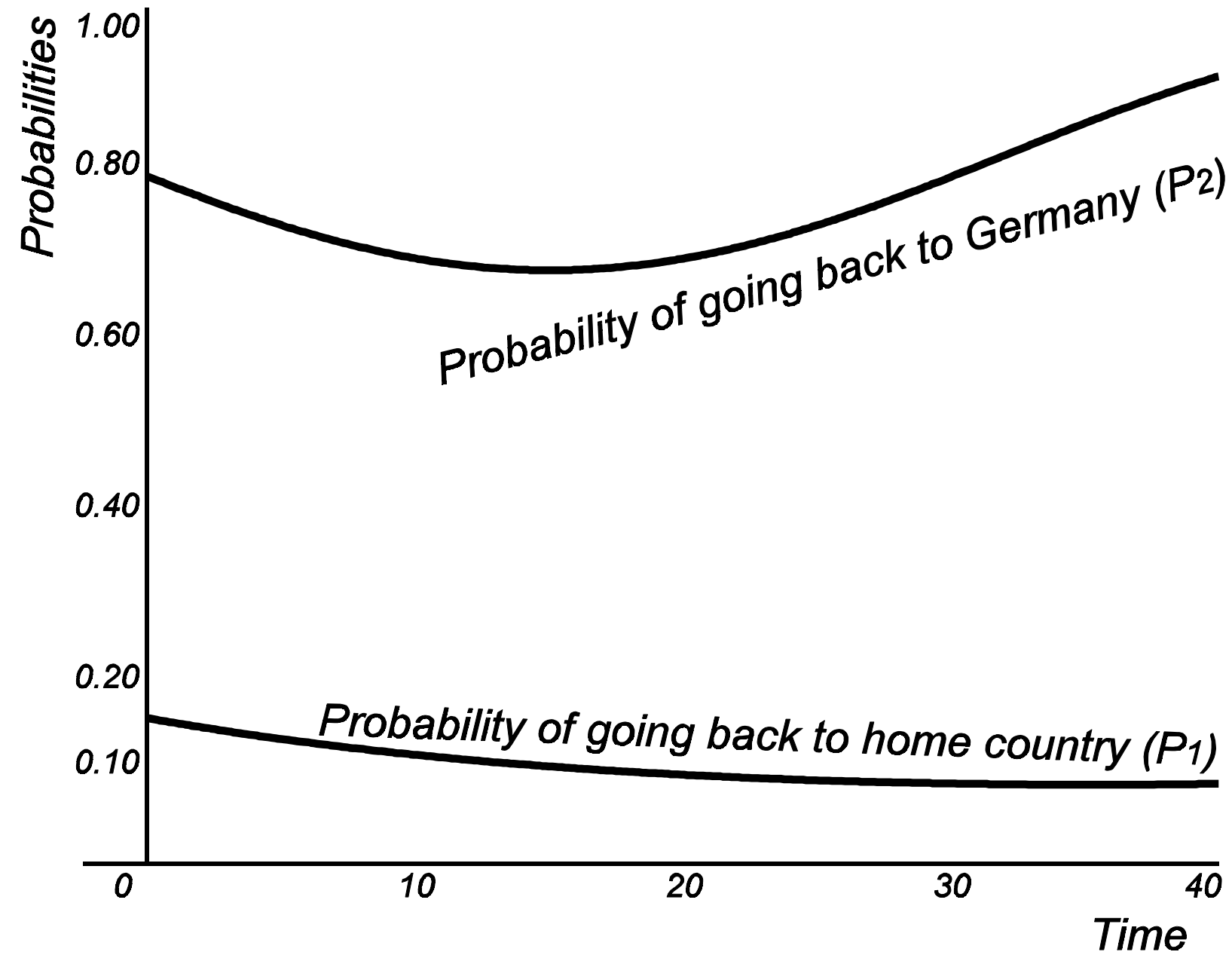

Figure 3: SIMULATED TRANSITION PROBABILITIES FOR SINGLE INDIVIDUALS OVER TIME

NOTE: $P_{1}$ and $P_{2}$ are conditional probabilities from different states and do not add up to one (see Table 2). The singles are sample average individuals who immigrated to Germany for the first time at age 20 and have no children. 


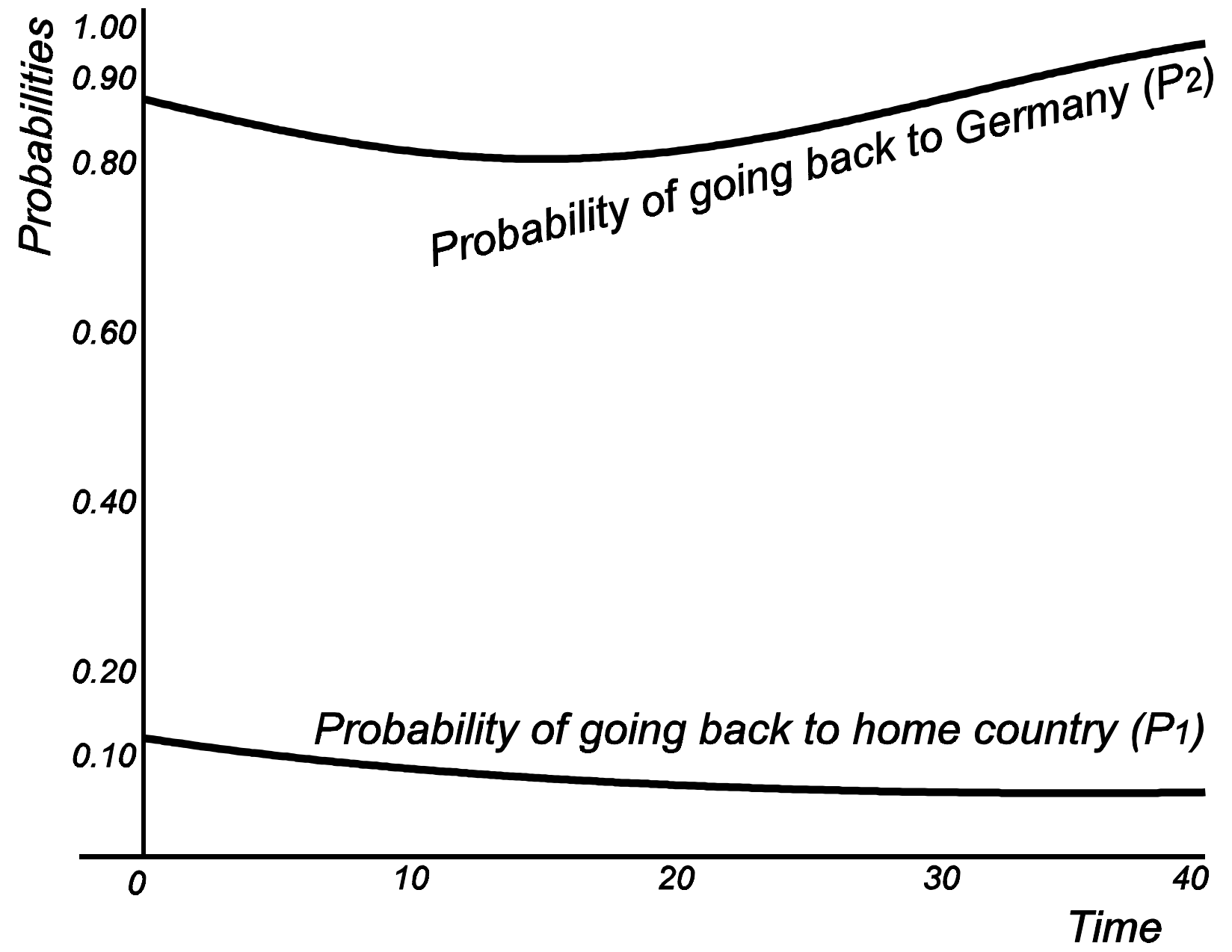

Figure 4: SIMULATED TRANSITION PROBABILITIES FOR MARRIED INDIVIDUALS OVER TIME

NOTE: $P_{1}$ and $P_{2}$ are conditional probabilities from different states and do not add up to one (see Table 2). The married individuals are sample averages who immigrated to Germany for the first time at age 20 and have no children. 